\title{
ALGUMAS CONSIDERAÇÕES SOBRE PSICOPATOLOGIA NA FILOSOFIA DE MERLEAU-PONTY*
}

Marcelo Georgetti Vieira, Reinaldo Furlan

\author{
Marcelo Georgetti Vieira \\ Psicólogo, pós- \\ graduando em \\ psicologia na \\ Faculdade de \\ Filosofia, Ciências e \\ Letras de Ribeirão \\ Preto, USP. \\ Reinaldo Furlan \\ Professor de filosofia \\ do Departamento \\ de Psicologia \\ e Educação da \\ Faculdade de \\ Filosofia, Ciências e \\ Letras de Ribeirão \\ Preto, USP.
}

RESUMO: O objetivo é destacar considerações de Merleau-Ponty sobre psicopatologias que revelam a experiência do corpo próprio como uma dimensão primordial de sentido. Valendo-se da psicanálise freudiana, que teria ao mesmo tempo elevado à ordem do sentido percebido o que, de acordo com a tradição, era considerado de ordem fisiológica (a sexualidade), e encarnado o que, também de acordo com a mesma forma de pensamento, era considerado de ordem espiritual (o pensamento), Merleau-Ponty elabora uma concepção concreta de existência, que evita a dicotomia cartesiana entre corpo e alma, ou entre orgânico e psíquico.

Palavras-chave: Merleau-Ponty, fenomenologia, psicopatologia.

ABSTRACT: Some considerations on psychopatology in MerleauPonty philosophy. The present paper aims at stressing MerleauPonty's considerations about the psychopathologies that reveal one's own body experience as a primeval dimension of the senses. Merleau-Ponty elaborated a concrete conception of existence and avoided the Cartesian dichotomy between body and soul, or between the organic and the psychic. He did that by using Freudian psychoanalysis, which had both promoted what was traditionally considered physiological (sexuality) to the category of perceived sense, and embodied what was traditionally considered spiritual (thought).

Keywords: Merleau-Ponty, phenomenology, psychopathology.

\footnotetext{
* Apoio: Fapesp.
} 


\title{
INTRODUÇÃO
}

O objetivo deste artigo é apontar para a experiência do corpo próprio e sua relação com o outro, e mostrá-la em sua função primordial de subjetivação, socialização e formação de sentido de mundo. Em particular, mostrar isso através da questão do “jogo" entre dois tipos de "saberes” que Merleau-Ponty vai distinguir desde a Fenomenologia da percepção (1945/1999): por um lado, há tudo aquilo que o sujeito sabe de uma maneira pensada, ordenada, objetiva; enfim, uma tese discursiva do mundo (e de si mesmo, uma vez que este se constitui nas relações estabelecidas com o primeiro). Por outro lado, existe um campo mais amplo de "saberes", que engloba e funda o primeiro, e no qual os sentidos são de uma ordem que não se restringe à do pensamento explícito, mas que representa a nossa postura primordial no mundo.

Será discutido como é possível “saber” algo e, ao mesmo tempo, não só ignorá-lo, como também mantê-lo à distância.

Em síntese, devemos explicitar melhor o que Merleau-Ponty quis dizer na seguinte passagem do seu livro Fenomenologia da percepção (1945/1999):

\begin{abstract}
"Sabe-se como a teoria da histeria foi levada a ultrapassar, com a noção de pitiatismo, a alternativa entre a paralisia (ou a anestesia) e a simulação. Se o histérico é um simulador, em primeiro lugar é em relação a si mesmo, de forma que é impossível colocar em paralelo aquilo que ele verdadeiramente sente ou pensa e aquilo que ele exprime no exterior: o pitiatismo é uma doença do Cogito, é a consciência tornada ambivalente, e não uma recusa deliberada de confessar aquilo que se sabe."
\end{abstract} (MERLEAU-PONTY, 1945/1999, p.223)

Ou seja, discutir como se dá esta autoenganação, que não representa um ato de consciência por parte do histérico, mas tem um fundo metafísico que diz respeito às trocas entre o corpo e a consciência e representa a noção de existência propriamente-dita, cujo sentido se encontra além da concepção objetivista do corpo e aquém da concepção intelectualista da consciência.

\section{O CORPO EM MERLEAU-PONTY}

De início, é importante discutir a noção de corpo para Merleau-Ponty, porque esta nos impõe um distanciamento de duas tradições de pensamento originárias do cartesianismo, que influenciam nossa forma de pensar de maneira direta: o espiritualismo ou intelectualismo, que é um desenvolvimento da concepção de cogito e se apoia na possibilidade de considerar o mundo a partir de um conjunto de ideias; e o realismo ou empirismo, que se posiciona em relação ao mundo considerando-o enquanto res extensa, um sistema de propriedades físicas, sub- 
metido a um conjunto de reações causais e determinadas, passíveis de serem apreendidas na forma de leis objetivas, que é do que se ocupam as investigações das ciências naturais. ${ }^{1}$

Em relação ao intelectualismo, o filósofo, logo no início de sua obra (1945/1999), dirige uma crítica à noção de "representação", afirmando que a experiência que temos do mundo não é abstrata, e nossas "ideias" são nada mais que pseudopresenças quando comparadas à evidência maciça do mundo que nos é aberto pela percepção — razão pela qual, para o filósofo, o mundo já é um “sistema de verdades". Nesse sentido, uma representação seria a cristalização de uma perspectiva que, descontextualizada do mundo de onde foi retirada, adquire seu ar de "eternidade" morta, acabada - ao passo que o mundo fenomenal, o qual experienciamos, possui ao mesmo tempo outras perspectivas possíveis, e sempre as ultrapassa a cada vez, justamente por não nos impor qualquer delas como necessária. O mundo, tal como nos é dado em nossa experiência ingênua, é inacabado em seus horizontes, sendo qualquer forma de representação sua uma experiência segunda apoiada sobre sua percepção. Quando o cientista considera a perspectiva de mundo elaborada por ele sem se questionar sobre a sua origem, desconsidera que tem ainda como pressuposto implícito essa experiência não tética ou presença surda do mundo como garantia de sua validade.

Já o problema que Merleau-Ponty vai pontuar no empirismo é que, desenvolvido em suas implicações, ele termina nos pressupostos do primeiro (o intelectualismo), pois, ao validar a existência de um mundo na ordem do puro em si, como faz o cientista clássico, este se põe no lugar de um observador puro, isento das amarras objetivas do mundo, que não se encontra em lugar algum e tem acesso ao mundo através de um "pensamento de sobrevoo”. De maneira que, ao constatar relações causais em processos que ocorrem no mundo, o observador se exclui enquanto participante de uma experiência a partir da qual se formam as significações com as quais este lida ao sistematizar seus "saberes". Assim sendo, as reflexões de Merleau-Ponty nos conduzem a uma dimensão mais originária, que é a dimensão vivida (pré-reflexiva), da qual as outras duas descritas (a objetiva e a subjetiva) são apenas abstrações, momentos secundários. É por isso que, para o filósofo, a ciência vai ser uma experiência segunda de mundo: mesmo as distinções objetivas por ela feitas pressupõem todo um conjunto de experiências que são necessárias não só para validá-las como também para sustentá-las.

Quando o foco das investigações é o corpo, as limitações que impossibilitam qualquer tentativa de se manter fiel a qualquer um dos estilos de pensamento

\footnotetext{
${ }^{1} \mathrm{O}$ espiritualismo e o realismo são concepções distintas e antagônicas da realidade na versão cartesiana, e têm, como correlatos epistemológicos, o intelectualismo e o empirismo, respectivamente.
} 
aqui citados tornam mais evidentes. Isto por causa da própria natureza do corpo, que é um “objeto estranho”: eu o percebo, ele ocupa lugar no mundo, mas não é composto apenas por relações causais e de exterioridade entre si, definidas por "partes extra partes”; ele é um objeto que também sou eu, sempre presente em meu campo perceptivo. Há este duplo sinestésico (de forma resumida: ser e se perceber ao mesmo tempo) que o cientista-psicólogo não pode deixar de lado ao descrever a experiência do corpo próprio.

Por exemplo, a frase: “tenho dor no pé” não indica apenas que há um lugar no espaço objetivo que origina a dor, tampouco que o pé nos envia sinais de que está doendo. Sou eu quem sente a dor em meu pé, enquanto uma forma de presença minha no mundo. Por outro lado, o corpo também não me é dado como um conjunto de representações, das quais a consciência teria plena posse intelectual; há uma opacidade do corpo em relação à consciência de si que situa o sujeito no jogo ambíguo entre aquilo que se vive e que se constata vivendo.

Sou meu corpo enquanto um conjunto de possibilidades que me inserem no mundo, abrindo-me um campo de experiências que, por sua vez, propiciam a emergência de novos sentidos, o que dá ao corpo um estatuto não só de experiência original como também originária. O próprio ato perceptivo já envolve um processo de significação. É através das funções impessoais do corpo que se estabelecem as relações do "sujeito epistemológico” com o mundo. Mesmo este termo deve vir entre aspas, pois se trata, em Merleau-Ponty, de dissolver por completo a existência hipotética de um pensamento "puro" que se baste por si só e de um corpo objetivo, considerado em separado; se ainda se pode falar de um cogito, este se encontra implícito no corpo, um cogito tácito, a presença de uma reflexividade que não se reduz ao nível tético, mas que se encontra em um nível mais fundamental: corporal. Um exemplo disso são as considerações de Merleau-Ponty sobre o tema da motricidade. Há, como observa o filósofo, uma “intencionalidade motora”, como pode ser observada na reação do corpo à picada de um mosquito: não é necessário representar o lugar em que o mesmo se encontra e considerar todas as possíveis trajetórias a serem percorridas pela mão em direção ao mesmo, de forma a optar por aquela que seja mais eficaz em acertá-lo; simplesmente sou meu corpo, não só enquanto uma forma de me situar no mundo, mas também como um campo de ação à minha disposição. É o que revela a noção de esquema corporal, que Merleau-Ponty aproveita da história da psicologia, sobretudo de Geld e Goldstein.

Não sou meu corpo apenas “do lado de dentro”; nesse sentido não há interioridade, mas relações concretas estabelecidas com o ambiente ao meu redor e a constatação das mesmas, com suas reminiscências que só podem ser pensadas a partir de meu corpo apreendido no "fora": é no mundo que me apreendo. Ao subir por um terreno inclinado, por exemplo, todo o meu corpo está voltado e 
adaptado a esta situação, todas as correções necessárias para garantir a manutenção de meu equilíbrio corporal são “instantaneamente” realizadas e postas em prática em função da ação que viso no todo, enquanto corporeidade que sou, sem haver necessidade de tomar consciência de todo o meu aparato fisiológico para que isto ocorra.

O corpo também é sempre o implícito considerado em quaisquer situações em que nos envolvemos. Mesmo quando nos prontificamos a ouvir uma palestra, o que por suposto nos exigiria um esforço no "nível ideológico", o tempo que nos é cobrado começa a nos desgastar em outro nível, começamos a ficar fadigados, nossa postura começa a nos incomodar - e não somos indiferentes a isso: nos impacientamos e esperamos com ansiedade crescente pelo fim da palestra ou por um intervalo, por mais interessante que seja o assunto exposto pelo palestrante ou seu carisma. Nosso posicionamento corporal sempre está presente e "contando" em nossos atos e situações vivenciadas; quando desviamos o olhar, o "saber subentendido” que é nosso corpo faz as correções necessárias para que percebamos a "permanência” dos objetos ao nosso redor, contrapostos a nosso olhar que, por sua vez, é o que está se movendo. Podemos ilustrar esta “acomodação fundamental” pela análise de uma patologia que envolve a relação entre fenômenos que, conforme a tradição, são considerados como "psíquicos”, mas que têm uma atuação na dimensão de nosso corpo, e que se enquadrariam, portanto, também na categoria de fenômenos “materiais", compondo assim um misto de fenômenos pertencentes a duas ordens diferentes de realidade. Referimonos ao caso do "membro fantasma”, em que o paciente relata que ainda sente o membro que perdeu em algum acidente; as discussões a esse respeito também se estenderiam ao caso de anosognose, sua contrapartida, em que o paciente desta vez "perde" um de seus membros, ainda que estes estejam aptos e funcionais do ponto de vista fisiológico.

A análise deste quadro patológico é mais um dos exemplos do estilo das reflexões que Merleau-Ponty (1945/1999) vai desenvolvendo, buscando por uma nova dimensão ontológica que contorne os impasses da metafísica cartesiana, assentados na diferença de natureza (substância) entre corpo e alma, ou pensamento e extensão. O paciente, no primeiro caso, ainda sente a presença de seu membro amputado; não podemos falar da presença de antigas representações, como seria o cunho das explicações intelectualistas, pois “....nenhuma explicação psicológica pode ignorar que a secção dos condutos sensitivos que vão para o encéfalo suprime o membro fantasma” (MERLEAU-PONTY, 1945/1999, p.116); mas uma explicação que por sua vez recorra a uma causalidade apenas fisiológica, como faria o empirismo, também não conseguiria dar conta do fenômeno, pois o fato do paciente aceitar a mutilação faz com que o membro fantasma "se 
encolha" e desapareça - ao passo que uma lembrança também pode voltar a trazê-lo à tona.

Visando contornar estas controvérsias, Merleau-Ponty (1945/1999) vai trabalhar a noção de existência, segundo a qual o sujeito deve ser considerado em sua totalidade global enquanto uma experiência encarnada, e não como um aparato físico-químico ou um conjunto de pensamentos. Tudo se encontra entrelaçado de maneira ambígua em seu movimento, e é nesta conjuntura que faz sentido a noção de recalque orgânico, utilizada para elucidar o caso do membro fantasma. Este termo é empregado por outros autores, mas chama a atenção de Merleau-Ponty por seu caráter nada cartesiano. Não se trata, propriamente, de afirmar que o paciente não sabe da perda de seu membro, pois é, na realidade, por "sabê-lo" que ele a evita. Mas esta recusa, este desviar-se, ocorre no nível que representa nossa postura diante do mundo e do outro, quando se abrem os sentidos para a consciência tética em si. Isso significa que o paciente do fenômeno do membro fantasma não aceita a verdade da perda do membro, na medida que procura manter o mesmo esquema corporal, com suas possibilidades motoras anteriores de ser no mundo, evitando se colocar em situações em que a perda do membro se tornaria manifesta. Isso pode ficar mais claro em uma passagem também pelos temas da sexualidade e da linguagem na mesma obra (1945/1999).

\section{A SEXUALIDADE E A FALA}

No capítulo “O corpo como ser sexuado”, Merleau-Ponty (1945/1999) discute as análises feitas pelo fisiólogo moderno Goldstein sobre o caso do paciente Schneider, que sofrera uma lesão no lobo occipital por conta de um ferimento de guerra. A proposta de fisiologia trazida por este médico diverge das tradicionais (como as de Pavlov) pois toma por referencial para explicar o homem não uma soma de arcos reflexos e outras funcionalidades mais primárias do comportamento, mas sim o posicionamento global do paciente no mundo, numa análise que possibilita encontrar uma dinâmica própria de funcionamento da patologia — o que, como vimos, entra em ressonância com as análises existenciais de Merleau-Ponty, que buscam o homem em suas relações concretas com o mundo.

Merleau-Ponty já havia considerado e analisado, capítulos antes, como a lesão sofrida pelo paciente acarretara alterações globais na estrutura do seu comportamento, tanto do ponto de vista prático como do conhecimento. No caso, o paciente em questão não dispunha mais do espaço de forma gratuita ou virtual, mas apenas de acordo com as forças de fato presentes em seu campo vital. Assim, era incapaz de compreender o pedido do médico para que levasse a mão até a testa, mas o fazia se um mosquito nela pousasse, e, à ordem para que imitasse o gesto do cumprimento militar, só podia fazê-lo tentando se inserir de novo 
nas situações realmente vividas antes enquanto soldado, isto é, procurando, com movimentos desajeitados, encontrar com seu corpo os movimentos que podia realizar outrora. Isto quer dizer que o paciente não perdera o significado das palavras em si, mas a capacidade de uma intencionalidade motora que dá origem à relação com o espaço de forma virtual, isto é, segundo uma projeção que transcende os dados reais de seu campo perceptivo: o paciente não podia mais viver o espaço de forma imaginária, e apreender na ordem do médico apenas o sentido essencial do gesto (o que revela também um problema de conhecimento), pois precisava reproduzir as mesmas condições efetivas de sua realização.

No caso da sexualidade, o mesmo esquema se revela. O paciente em questão demonstra não "saber direito o que está fazendo" quando posto em uma situação sexual: apresenta todas as reações relacionadas a este tipo de ocasião, porém sempre em resposta ao "estímulo" mais imediato, sem tomar a iniciativa de qualquer atitude que rumasse em direção à sua "consumação"; tampouco se trata de dizer que houve um enfraquecimento das representações do paciente, pois a área afetada envolve as funções visuais - no caso da sexualidade também estão envolvidas as sensações táteis, e não houve perda do significado destas representações. Tudo nos leva a considerar a sexualidade enquanto uma ordem de compreensão não tética, que se encontra enraizada nas funções básicas de nosso corpo, enquanto uma de suas possibilidades originárias de se dirigir ao mundo.

Da mesma maneira que estamos sempre postos em relação com um mundo e situados em seu espaço de uma forma mais originária do que por meio dos pensamentos, é também pela sexualidade que somos postos em um mundo da intersubjetividade, de significações eróticas intrínsecas ao ato perceptivo. Merleau-Ponty elogia a psicanálise por ser uma de suas aquisições mais duráveis ter demonstrado que os processos que se operavam na sexualidade, antes considerados como "orgânicos" ou "mentais", tinham agora suas raízes em um sujeito encarnado, o que fechava o circuito na relação entre um "sujeito do conhecimento" e um "sujeito agente", impondo às formas tradicionais de pensamento — de origem cartesiana - uma revisão ontológica que reivindica uma nova ordem: a das "relações concretas" e do "simbolismo encarnado".

Esta era a ordem aspirada por G. Politzer (1928/1998) em seu livro Crítica dos fundamentos da psicologia: a psicologia e a psicanálise; porém, este acusava Freud de estar elaborando uma teoria híbrida e de princípios epistemológicos obscuros e contraditórios. Na obra citada, é analisada a "Interpretação dos Sonhos” de Freud, considerada um dos seus principais escritos. Politzer faz a distinção entre dois tipos de psicologia: por um lado, a concreta, que se atém à dimensão do vivido, ou, para utilizar um dos termos do autor, do drama (considerado sem a conotação romântica do termo); por outro, a abstrata, que se vale de terminologias 
mentalistas/fisiologistas para explicar o funcionamento do aparelho psíquico. A crença em um mundo interno — ou de relações causais descontextualizadas de um campo de ação no qual o indivíduo se encontra — se torna desnecessária; não precisamos mais, por exemplo, do que a situação que Otelo vive para compreendermos seus ciúmes por Desdêmona. Assim sendo, é a partir de um enfoque concretista que um arcabouço psicológico legítimo poderia ser elaborado, e as explicações psicológicas por força deveriam envolver a participação do protagonista de uma experiência sempre vivenciada em primeira pessoa para que possa receber seu atestado de "psicológica".

Foge, portanto, de uma Psicologia — dentro da concepção do autor (Politzer) - outras formas de investigação que se fiavam no modelo das ciências naturais e tratavam o indivíduo como uma instância submetida a relações causais observáveis em terceira pessoa. E, se por um lado há na psicanálise uma contribuição para uma psicologia concreta em suas análises que partem de uma situação vivida - como o Édipo, por exemplo — , por outro, estas perdem seu valor ao caírem em um abstracionismo desnecessário, como, por exemplo, fazer de um indivíduo “... uma sucessão de processos impessoais” (POLITZER, 1928/1998, p.128) presentes "no" inconsciente, que marginalizam o sujeito agente de sua própria ação. Segundo a análise de Politzer, o que teria levado Freud a postular tal concepção de inconsciente seria a pretensão de garantir alguma “cientificidade” à sua Psicanálise, elaborando-a inspirado em modelos energéticos e causais da Física Clássica; e também o "postulado do pensamento narrativo/discursivo" (segundo o qual para cada ação haveria uma enunciação "em pensamento" para sua execução). Assim, uma vez que estes não se encontravam em uma experiência da qual o indivíduo tivesse "consciência”, por dedução deveriam estar "no" inconsciente. Encontramos então o que Politzer enxergava de contraditório na teorização psicanalítica, e, neste ponto, Merleau-Ponty vai dar desenvolvimento a uma concepção psicológica de homem que entra em ressonância com a crítica politzeriana considerada, embora evitando a distinção entre processos em primeira e em terceira pessoas, procurando, com exatidão, o meio termo a partir do qual essas distinções são abstratas ou secundárias. No caso, e ao contrário de Politzer, Merleau-Ponty não vê a fisiologia como processos físico-químicos em terceira pessoa (linguagem da física), mas como o princípio de inserção do ser no mundo do organismo vivo e também do homem. A fisiologia, no caso, deve ser compreendida na relação do organismo com o meio — portanto, em sua abertura e relação com o mundo próprio à espécie. Por isso a psicologia é a ciência concreta do comportamento do ser vivo, e a fisiologia, considerada em si mesma ou apartada das relações do organismo com o meio, é abstrata.

Por outro lado, a relação de Merleau-Ponty com a psicanálise não parou de se estreitar ao longo dos anos. A Fenomenologia da Percepção estava imbuída do 
sentido de se afastar das especulações freudianas do aparelho psíquico, quando de caráter objetivista, e de um espírito filosófico que se acreditava necessário para corrigir o freudismo de seus "escorregões” epistemológicos com suas explicações causais e energéticas, protegendo, assim, aquilo que seria sua descoberta original, a saber, uma hermenêutica capaz de revelar os sentidos da vida do sujeito - aquém de seus atos explícitos de consciência. Anos depois, Merleau-Ponty (1960) observa, dada a aceitação e expansão da psicanálise na cultura ocidental, que o risco que ela corre passa a ser outro - mais precisamente, e ao extremo do objetivismo anterior, a sua espiritualização. Então, o caráter enigmático dos fatos que a psicanálise nomeava, cujos termos objetivistas ao menos preservavam, é dissolvido numa acepção superficial e rápida do inconsciente, contra o qual o filósofo recomenda, ao invés de se tentar corrigir o freudismo naquilo que ele trazia do escolho cientificista da época, como ele próprio havia tentado, ler Freud como se lê um clássico, isto é, mais como marcação de um campo problemático a ser pensado ou investigado, do que segundo o léxico comum de alguns de seus termos. Em suas palavras, “Ao menos as metáforas energéticas ou mecanicistas guardavam contra toda idealização o rastro de uma intuição que é uma das mais preciosas do freudismo: aquela de nossa arqueologia" (Ibid., p.282).

Feito esse reparo, e voltando aos termos da Fenomenologia da Percepção, é nessa região anônima, disposta pela relação do corpo com o mundo, que se destaca nossa existência em primeira pessoa, antes como uma expansão da primeira do que como separação propriamente dita, pois seus limites não são nunca claros ou bem definidos. Mesmo nas atividades culturais por definição, nossas decisões mais explícitas têm algo de estereotipado, de uma generalidade própria da época, assim como o mundo se nos torna natural com o decorrer de nossas experiências.

Em particular, a sexualidade se encontra difundida em nosso meio de maneira ambígua, nosso mundo percebido está impregnado de significação afetiva. Ora, é justo por envolver nossa adesão ao mundo e aos outros que nossa sexualidade é a chave da constituição de nossa história pessoal, conforme aponta a psicanálise, o que faz os signos sexuais privilegiados para a compreensão do sentido de nosso ser.

Também na linguagem, assim como na sexualidade — cuja noção deixou o campo mais restrito da biologia para ser compreendida dentro do campo da intersubjetividade (enquanto drama, falando em termos politzerianos) encontramos a mesma função corpórea primordial por meio da qual as coisas passam a ter um sentido para nós, e assim, os mesmos esquemas (intelectualista e empirista) serão recusados por Merleau-Ponty na compreensão do fenômeno da fala. O primeiro, porque desconhece a potência de significação do gesto ou da palavra, fazendo deles apenas invólucros de um pensamento que seria o único portador da significação. Como diz Merleau-Ponty, para o intelectualismo 
há um sujeito que fala, mas é o sujeito pensante - a fala serve apenas para a transmissão de seu pensamento. Mas, assim, não se compreende o trabalho do escritor, e nem mesmo porque procuramos um pensamento através da fala, se pressupomos um pensamento já possuidor de suas significações. De fato, é tardia na história da filosofia a descoberta do valor da linguagem para o pensamento, ou de como ela representa a sua realização, assim como o sentido da música ou da pintura se faz por seus próprios meios de expressão. Quanto ao empirismo, que procura reduzir o sentido das palavras à associação entre os estímulos físicos nelas presentes com aqueles do meio em que se encontra o organismo, ele conclui que não há sujeito falante, e que "o homem pode falar do mesmo modo que a lâmpada elétrica pode tornar-se incandescente” (MERLEAU-PONTY, 1945/1999, p.238). Em última instância, os princípios do empirismo, analisados por este autor, cortam o homem do contato com a verdade - o que é um contrassenso, afinal, o cientista ou psicólogo não pode se considerar além das condições que estabelece no conhecimento do comportamento do outro. Como dissemos antes, o empirismo se utiliza da mesma tese do intelectualismo, pois pressupõe um sujeito de conhecimento livre de condicionamentos, um observador absoluto, capaz de sobrevoar a experiência enquanto conhece. Ora, no caso da linguagem, Merleau-Ponty pretende superar essas duas posições que parecem antagônicas, por meio da assunção da palavra como portadora do próprio sentido.

Na Fenomenologia da percepção (1945/1999), Merleau-Ponty vai buscar a compreensão da linguagem pela compreensão da fala, e desta por meio da compreensão do gesto. A fala é um gesto, e como este, brota do movimento de significação do próprio corpo em direção ao outro. Tudo se trata, então, de compreender o sentido desse movimento, e de sua compreensão pelo outro, que é da ordem do corpo e não do pensamento, entendido este como um processo de representações puras, ou espécie de visão mental da ideia ou do significado. É no mundo que nos encontramos e nos entendemos (ou não nos entendemos), diz Merleau-Ponty, querendo com isso mostrar que o sentido das palavras se encontra no sentido do comportamento de que elas participam de maneira ativa, isto é, ajudando a construí-lo, tecendo com todos os outros sentidos - táteis, motores e visuais - um único movimento de sentido. É pelas considerações de Husserl sobre aquilo que chamou de "transgressão intencional" que Merleau-Ponty inicia mesmo a compreensão do gesto ou do comportamento do outro. Ou seja, há certos espetáculos (o comportamento do outro, mas também de certos animais) cujo sentido investe o nosso corpo, quando parecia que éramos nós que o constituíamos através da própria consciência. Assim, parecia que éramos nós que compreendíamos o sentido do outro por meio de um ato de nossa consciência, e, de repente, nos vemos investidos pelo sentido de seu comportamento, que parece vir habitar nosso próprio corpo. Tudo se passa como se a intenção do 
outro viesse habitar nosso próprio corpo, revelando-nos, e muitas vezes criando (e esse será o caso da aprendizagem da linguagem ou do comportamento em geral), potencialidades próprias de comportamento até então desconhecidas. O importante é frisar o caráter corpóreo dessa assunção de sentido, o que também pode ser evidenciado com a análise do exemplo da criança que presencia o intercurso sexual dos pais. A criança pode compreender parte do significado do comportamento presenciado, como a própria percepção dos pais já havia lhe revelado em parte o sentido de que formam um casal; mais ainda, o comportamento sexual dos adultos lhe propõe um encaminhamento de sua própria libido, e nesse sentido antecipa um comportamento futuro, como mostram com clareza as brincadeiras infantis; mas o acontecimento parecerá bizarro à criança enquanto não sentir no próprio corpo as mesmas possibilidades sexuais presenciadas no comportamento dos adultos. É também por isso, seguindo a mesma lógica, que para nós é mais fácil compreender a mímica sexual dos cães do que a do besouro ou do louva-a-deus.

Merleau-Ponty falará, anos depois, em "magma ou promiscuidade dos homens no mundo” (1959-1961/1996, p.204) para expressar essa experiência intersubjetiva, que destacamos a partir da experiência do olhar:

“Esta mistura e esta invasão (de um sobre o outro) existem já porque nós vemos, isto é, vemos os outros verem, com uma sutileza extraordinária, vemos com os olhos dos outros desde que tenhamos olhos (...) Isso parece sexto sentido porque cremos que se vê apenas coisas visíveis ou qualidades: mas eu vejo corpos dirigidos para o mundo e para o mesmo mundo que eu vejo, seus gestos ínfimos, eu os esposo, eu os vejo do interior. Os homens também são homens-gignognes ${ }^{2}$ — se se pudesse abrir um, nele encontraríamos todos os outros como nas bonecas russas, ou antes, menos bem ordenados, em um estado de indivisão." (MERLEAU-PONTY, 1959-1961/1996, p.211)

Ora, o comportamento linguístico é um desdobramento dessa mesma potencialidade de troca de sentidos que ocorre na experiência do olhar.

É o que também revelam as análises de Lagache sobre a patologia da "Alucinação Verbal", consideradas por Merleau-Ponty em um de seus cursos na Sorbonne (1949-52/1990). Como outras experiências patológicas, estas evidenciam dimensões não percebidas ou pouco notadas na experiência normal.

Nesta condição patológica, as relações linguísticas entre o "eu” e o "outro" se encontram invertidas ou misturadas de maneira confusa. Isto se manifesta no fato do doente ouvir suas falas como se estas viessem diretamente de outrem,

\footnotetext{
${ }^{2}$ Referência à personagem do teatro infantil que se apresenta como mãe de muitos filhos, que saem debaixo de suas saias.
} 
ou ouve as falas do outro como se fossem suas próprias palavras, havendo ainda outras variações possíveis, como uma compulsão à expressão involuntária (impulso verbal), ou como o não reconhecimento da origem das falas que se ouve, como se estas viessem de ninguém (MERLEAU-PONTY, 1949-52/1990, p.64). De qualquer modo, depreendemos que o eixo central destas patologias é uma despersonalização da fala, quer dizer, o apagamento dos limites entre o eu e o outro, o que nos revela, por isso mesmo, que ambos formam um só sistema — daí a possibilidade dessa indistinção entre a voz própria e a do outro ou confusão alucinatória, que exacerba a presença do outro em mim ou de mim no outro.

Nesse sentido, também, Merleau-Ponty (1949-52/1990) indica que Freud passou da oposição inicial entre o dentro e o fora (os desejos sexuais e a moral, eu e o outro) para sua implicação recíproca. É a mim mesmo que persigo no outro, ou ao outro, em mim (sadomasoquismo), eu e os outros estamos sempre implicados. Por isso a "solução", ou a cura do conflito, não se limita a uma gratificação objetiva do desejo reprimido, mas requer rearranjo do sentido da relação com o outro ou o mundo.

Em síntese, deve-se, portanto, recusar a ideia de indivíduo enquanto entidade solipsista, para reconhecê-lo num sistema em que as relações eu-outrem estão presentes de forma indissociável.

É o que se constata no caso da jovem afônica tratada por Binswanger, e citado no capítulo sobre “O corpo como ser sexuado” (MERLEAU-PONTY, 1945/1999). Neste caso, a jovem foi proibida pela mãe de ver seu amado. Decorrente dessa proibição, aos poucos foi diminuindo seu apetite e perde de vez sua voz. Pela leitura realizada por Merleau-Ponty, a voz simbolizava, para a moça, o canal de comunicação que a põe no circuito de relações com outrem. Encontrando-se em uma intensa situação conflitante entre o desejo de estar com seu amado e a impossibilidade de romper com a autoridade da mãe, e sem forças para contorná-la, ocorre a mudança pela qual o que tinha valor para um caso singular adquire generalidade, deixa de ser uma forma de lidar com um caso atual e passa a valer para todas as relações assumidas com os outros. Sua impossibilidade de se unir ao amado se torna uma "tragédia", na qual se vê impossibilitada de se relacionar com todo o mundo — ou, segundo Merleau-Ponty: "A vertigem do amuo é tal que ele se torna amuo contra X, amuo contra a vida, amuo absoluto” (1945/1999, p.225).

Então a moça se vê encerrada em uma estrutura de conduta histérica que opera segundo uma dinâmica própria, e porta o próprio sentido. Isto porque ela não escolheu, no sentido restrito do termo, sua histeria ou condição patológica. Esta apenas se desdobrou em coerência com sua vida, tal como esta se desenrolou a partir do momento da proibição, vivenciada como traumática. Seu sintoma é expressivo do conflito que não consegue enfrentar, superar ou contornar - a 
perda da voz seria uma atualização dessa situação, e que reduz seu campo de possibilidades de ser no mundo com os outros.

Da mesma forma, mas em sentido inverso - e isso também vale para o caso do fenômeno do membro fantasma — a moça afônica só pode superar seu estado de histeria se vivenciar um processo de mudança que a afete em seu modo de ser concreto, e que altere, portanto, o sentido da sua postura diante do mundo e do outro a que nos referimos. Assim sendo, o que vai possibilitar a cura é o fato de nosso corpo ainda nos manter abertos a este tipo de mudança. Às vezes, basta a pressão da mão do médico no pescoço da moça para restituir-lhe a voz e recolocá-la no circuito da comunicação com o outro. Ou seja, é no nível prétético de formação de sentido de mundo, em que o corpo se relaciona com o mundo e o outro - através de todos os seus membros e órgãos, unificados e relacionados entre si no processo de ser no mundo - , que podemos adoecer ou nos curar. É assim, também, que se deve entender a possibilidade de, ao mesmo tempo, "saber" e não saber algo, mais precisamente agora, de viver um sentido de mundo que não se reduz ao que sabemos por nosso pensamento de mundo.

Recebido em 1/9/2008. Aprovado em 17/7/2009.

\section{REFERÊNCIAS}

MERLEAU-PONTY (1943/2006) A estrutura do comportamento. Trad. de Márcia Valéria Martinez de Aguiar. São Paulo: Martins Fontes.

(1945/1999) Fenomenologia da percepção. Trad. de C.A.R. Moura. São Paulo: Martins Fontes.

(1990, 1949-1952) Resumo de cursos na Sorbonne, Vol. II. Trad. de Constança M. César. Campinas: Papirus.

(1956-1960/2000) A natureza — Notas de cursos no Collège de France, 1956-1960 Texto estabelecido e anotado por Dominique Séglard. Trad. de Álvaro Cabral. São Paulo, Martins Fontes.

(1960/2000) “L'oeuvre et l'esprit de Freud et son importance dans le monde moderne — Préface à l'ouvrage de A. Hesnard", in Parcoux deux, 1951-1961. Lagrasse: Verdier.

(1959-1961/1996) Notes de cours, 1959-1961 (Texte établi par Stéphanie Ménasé). Paris: Gallimard.

POLITZER, G. (1928/1998) Crítica dos fundamentos da psicologia: a psicologia e a psicanálise. Trad. de M. Marciolino \& Y. M. Campos Teixeira da Silva. Piracicaba: Unimep.

Marcelo Georgetti Vieira

marcelo_psi@yahoo.com.br

Reinaldo Furlan

reinaldof@ffclrp.usp.br 